\title{
Macroscopic Findings Assessment Test
} Code

National Cancer Institute

\section{Source}

National Cancer Institute. Macroscopic Findings Assessment Test Code. NCI Thesaurus.

Code C119876.

A character or string that represents the short code name of the macroscopic findings assessment. 